\title{
ON THE FORMAL APPROACH TO DESCRIBING NATURAL LANGUAGE. NOTES ON THE MARGIN OF LEŚNIEWSKI'S ONTOLOGY
}

\begin{abstract}
This article is an attempt to recreate the intuitions which accompanied Leśniewski when he was creating his calculus of names called Ontology. Although every reconstruction is to some extent an interpretation, and as such may be defective, still, there are reasons justifying such reconstruction. The most important justification is the fact that both Leśniewski and his commentators stressed that ontology originated from reflections about ordinary language, in which sentences such as $A$ is $B$ appear in one of the meanings associated with them in Ontology, and that the users of the Polish language use such sentences accordingly and properly identify them. Assumed it is so, let us try, based on Leśniewski's guidelines as well as comments and elaborations on Ontology (Leśniewski 1992: 364-382, 608-609; Kotarbiński 1929: 227-229; Rickey 1977: 414-229; Simons 1992: 244; Lejewski 1960: 14-29), to evaluate the accuracy of this approach, referring also to certain knowledge of the Polish language. To make it clear, this article is not about Ontology as a formal theory of language. It is solely an attempt to assess whether some syntactical constructs of the Polish language and this language's properties are significant conditions of a proper understanding of Ontology, and whether Ontology is, in fact, in a relationship with the ethnic language of its author.
\end{abstract}

Keywords: Leśniewski's Ontology, formal approach to natural language, Polish language.

There are two distinct views on the nature of formal languages. The first one says that formal systems are systems of ideal languages equipped with strict rules which natural languages lack. These systems are not in a relation to any ethnic language, they exist individually and independently as constructs of the human mind different from natural languages. The other view assumes that the theory of formal systems is an idealising theory of natural language. From the point of view of applying formal systems in the study of natural languages, the concept promoting scientific idealization seems more useful (Black 1944: 241). 


\section{Halina Święczkowska}

Ontology together with Protothetic and Mereology compose the whole of Leśniewski's systems - a totality which, per its author's intentions, was supposed to embody the program of constructing a system covering all deductive knowledge. According to Leśniewski, these systems may be one of the possible foundations for a system of mathematics. In this respect, Leśniewski's intentions are comparable with the objectives assumed by Frege. Leśniewski studied Frege's works thoroughly and wrote that Frege's Grundgesetze der Arithmetik was the most imposing embodiment of achievements on the solidity of deductive method in the history of validating mathematics since ancient Greece (Leśniewski 1992: 177). A critical analysis of Whitehead's and Russell's works ${ }^{1}$ (Leśniewski 1992: 606-607) led him to many fundamental ideas. It is important to stress that the most important idea was a consistent distinction between language and metalanguage. A logical system must be constructed in an objective language and commented in metalanguage (Woleński 1983: 134-138).

Historically, the first deductive system was the Mereology presented by Leśniewski in 1916, inspired by Russell's antinomy. Mereology is an extralogical theory, meaning that its primitive concept is not a logical constant. Mereology is a theory of classes, but contrary to regular set theory, it focuses on collectives. Leśniewski believed that the source of Russell's antinomy lies in the confusion of the notion of set in the collective and distributive sense. In 1920, Leśniewski, aware of the fact that Mereology requires a base in the form of a more general theory, constructed a system of calculus of names, which he called Ontology. Ontology first originated as an elementary theory with a system of hierarchical semantic categories built upon it later. At the same time, Leśniewski became interested in propositional calculus, which he generalised into a system of Protothetic.

According to some, Leśniewski's Ontology is the most interesting logical system developed by him (Simons 1992: 277). Structurally, but not historically, it is based on Protothetic. Ontology is explained as a propositional calculus. Leśniewski himself wrote that the theory he calls Ontology is a modernised version of "traditional logic", related to Schröder's theory of individuals (Leśniewski 1992: 177). Formally, Ontology is created by adding to the categories present in Prototethic a new and basic, together with the sentence, semantic category of name $(\mathrm{N})$ and categories of functors derivative of those two categories. The resulting syntactic categories form two groups: those with an index beginning with " $\mathrm{S}$ ", and those with an index beginning with "N", in standard fractional notation. The former are called propositional categories, the latter nominal (Simons 1992: 230). ${ }^{2}$ The rules and axioms of Prototethic are accompanied by rules on name expressions, 
called Ontological definitions, and the rule of Ontological extensionality. A new axiom is introduced to Ontology, based on a new primitive symbol $\varepsilon$, with an $\frac{\mathrm{S}}{\mathrm{NN}}$ index.

Leśniewski rather preferred the term "semantic category" than "syntactic category", although he did not think this meant that every expression relates to a certain object as its denotation. Leśniewski's categories expanded upon Husserl's Bedeutungskategorien, and the choice of terminology only highlights the fact that the constant expressions in his languages had an intended meaning (Simons 1992: 278). Leśniewski's system of categories was developed for the purposes of the systems of logic constructed by him. By defining the concept of semantic category of his symbolic language, he could limit himself to purely structural characteristics, i.e. he could do with presenting purely external characteristic possessed by two expressions always and only if they belong to the same semantic category. However, when the general idea of this concept is applied to the classification of words and phrases of ordinary language, it is difficult - faced with the ambiguity of this language - to do only with structural distinctions; it also must refer to the meaning of classified expressions (Ajdukiewicz 1960: 196 and further). Leśniewski's system of categories is interpreted as a linguistic approach, since the categories describe expressions and not objects (Woleński 1985: 40).

Leśniewski's commentators stress that Ontology does not have - contrary to Prototethic, which is a generalization of propositional calculus a simple equivalent in known theories of logic (Simons 1992: 227). The genesis of Ontology is described in On the Foundations of Mathematics. Leśniewski (1992: 367-368) mentions that the semantic analysis of singular sentences like $A \varepsilon b$ and the relationships between such sentence became, in 1920, the focus of his interest for a time. He decided to base all of his reflections conducted with such sentences on some clearly formulated axiomatization. In relation to such axiomatization, Leśniewski required that no "constant" terms should appear in it with the exception of the symbol $\varepsilon$ in propositions of the type $A \varepsilon b$ and the terms which appear in "deductive theory". He wrote that for his theoretical purposes, at the time, he would not have accepted as sufficient any axiomatization that, according to his knowledge, would not guarantee the possibility of using "symbolic" equivalents of theses, stating respectively, that:

1. some $\mathrm{a}$ is $\mathrm{b}$ when and only when, for some $\mathrm{X},(\mathrm{X}$ is a and $\mathrm{X}$ is $\mathrm{b})$,

2. if $\mathrm{A}$ is $\mathrm{b}$, then $\mathrm{A}$ is an object,

3. every $\mathrm{a}$ is $\mathrm{b}$ when and only when (some object is a, and for any $\mathrm{X}$, if $\mathrm{X}$ is $\mathrm{a}$, then $\mathrm{X}$ is $\mathrm{b}$ ), 


\section{Halina Święczkowska}

4. $\mathrm{A}$ is the same object as $\mathrm{b}$ when and only when, (A is $\mathrm{b}$, and $\mathrm{B}$ is $\mathrm{A})$,

5. at most one object is a when and only when, for any $\mathrm{A}$ and $\mathrm{B}$, if $\mathrm{A}$ is a, and $\mathrm{B}$ is a, then $\mathrm{A}$ is the same object as B, and

6. A is a when and only when, (each A is a, and at most one object is A). These explanations are sufficient to recognize Ontology as an actual calculus of names with "is" as a primitive functor.

As Kotarbiński comments, Leśniewski freed himself of connotation of truth in subject-predicate singular sentences. Previously, influenced by Mill, Leśniewski claimed that a proposition $A$ is $B$ is true if the object denoted by the subject has a property connoted by the predicate. However, reflection led him to come up with a formula free from "connotation", and, consequently, free from "property". This formula states that a singular subject-predicate sentence is true if the object denoted by the subject is the object denoted by the predicate (Kotarbiński 1929: 253-254, Leśniewski 1992: 371-374). As indicated by J. Woleński (1985: 210), this is exactly what supports the ontological thesis that apart from common names, proper names and individuals, we do not need anything else. At this point it is enough to add an Ontological thesis: only concrete individuals exist, which is essentially an extra-logical assumption, though supported by Leśniewski's Ontology. Kotarbiński was one of the first commentators and popularisers of Leśniewski. Ontology equipped him with the necessary formal tools for his construction of reism. As a nominalist, Leśniewski is ideologically close to Kotarbiński. Therefore, it seems plausible that Ontology was an attempt to "logically" grasp the general theory of objects, while reism provided metaphysical arguments (Woleński 1985: 210, 219).

According to Leśniewski, Ontology formulates only certain general rules of existence. This vague explanation appears insufficient to the author himself, since he quotes Kotarbiński's commentary on this matter with full approval. When presenting his own version of the calculus of names, Kotarbiński writes that it is based on Leśniewski's system he knows from manuscripts, and which was presented to wider audiences in the form of lectures.

We consider that system of the calculus of terms to be the most natural, most evolved and most practical in application of all the systems known to us. At the same time it is most closely connected with traditional Aristotelian formal logic, of which it is an extension and improvement, while, on the other hand, it is the terminal point of the endeavours to build the calculus of terms in logic. [...] Let it be added that Leśniewski called his system an "ontology", in conformity with certain terms already used 
(like the "ontological principle of contradiction" [...] in Lukasiewicz [...]). The term is further justified by the fact that the only primitive term which appears in the axiom of the system in question is "est", or "is", which corresponds to the Greek $\epsilon \sigma \tau$. Now if we want to emphasize that, we may call the system after the appropriate Greek participle, namely ov [...], which means "being". If we nevertheless do not use here the word "ontology" as the name of the calculus of terms, we do so only for fear of a misunderstanding. That term has become accepted in another role - namely that of enquiry into the "general principles of existence", conducted in the spirit of certain parts of the Aristotelian "metaphysical" books. It must, however, be admitted that if the Aristotelian definition of the supreme theory [...] be interpreted in the spirit of a "general theory of objects", then both the word and its meaning are applicable to the calculus of terms as expounded by Leśniewski (Kotarbiński 1966: 210-211).

Understanding Leśniewski requires from the reader a non-standard approach to the category of name. Nominative expressions in Leśniewski, distinct from any other logic systems, may denote more than one object or may not denote anything, while being treated as fully individual expressions by him. The assumption about the individuality of nominative expressions is understandable, names are awarded a similar status in Frege's theory. Noticing a structural distinction between nominative expression, Frege treats them identically on a semantic plane and gives them individual denotation. This in itself is sufficient evidence of the distinctiveness of his approach from the understanding of names in Ontology. There are also various other differences, namely the fact that names may occur in sentences, in Frege's theory, only as subjects. An object's name cannot be a grammatical predicate, since the two are not the same. A predicate denotes a single argument logical function, called by Frege a concept, a name denotes, on the other hand, an object it indicates. In the article, On Concept and Object, Frege analyses (1960: 183) several sentences:

1. Der Morgenstern ist ein Planet. [The Morning Star is a Planet.]

2. Der Morgenstern ist die Venus. [The Morning Star is Venus.]

In the first sentence, the object falls under the concept. This relationship is non-symmetrical, as opposed to sentence 2, which is an equivalent sentence. In this sentence, the word is is not only a copula, but also a contentsignificant component of the predicate, which is not wholly contained in the word Venus. The second sentence may be rendered into an equivalent sentence:

3. Der Morgenstern ist nichts anderes als die Venus. [The Morning Star is no other than Venus.] 


\section{Halina Święczkowska}

What was previously contained in ist die is now contained in the phrase ist nicht anders ais die, where ist is not, in fact, only a copula. What is predicated here is therefore not Venus, but rather nicht anders als die Venus, and the phrase denotes a concept with only one object falling under it.

In Ontology, the matter of syntactical functions possible for nominal expressions is determined by the affiliation of such expressions to the same semantic category. The sentence This man is Socrates is not interpreted in the same way in the language of Ontology, as it is in Frege. It is an individual sentence constructed with an $\frac{\mathrm{S}}{\mathrm{NN}}$ sentence functor of two nominal arguments: this man and Socrates. ${ }^{3}$

Here let us take a closer look at the so called singular sentences in the Polish language, in particular at those which, according to Leśniewski and Kotarbinski, fit the $A$ is $B$ scheme. According to the theory, the word jest $[i s]$ in such sentences corresponds to the Ontological epsilon. The only axiom in Ontology with the epsilon as the primitive symbol is the following:

$$
\begin{aligned}
{[a b](a \text { est } b \equiv \exists x(c \text { est } a) \&[c](c \text { est } a} & \rightarrow c \text { est } b) \& \\
& {[c d]((c \text { est a\&d est } a) \rightarrow c \text { est } d))) . }
\end{aligned}
$$

The axiom states that (i) $a$ is non-empty (something is $a$ ), (ii) whatever is $a$, is also $b$, and (iii) there is one $a$.

With this in mind, we must take the sentences into consideration:

1. Ja jestem. [I am.]

2. Człowiek jest istota myślaca. [A human is a thinking being.]

3. Ktoś jest na strychu. [Somebody is in the attic.]

4. W sypialni jest balagan. [In the bedroom there is a mess.]

5. Myśleć jest niebezpiecznie. [To think is dangerous.]

They do not fit the scheme of singular sentences, although each one for a different reason. Sentence 1 may be interpreted as a sentence stating my existence. Sentence 2 is a general sentence, although the lack of clear quantification makes it ambiguous, and in certain readings it may be treated as an Ontological sentence. (This may be an ellipsis of the sentence: Ten czlowiek, o którym mówie, jest istota myślaca [The human I am talking of is a thinking being]). In sentences 3 and 4 we are dealing with a certain space-time relationship, which is denied to the Ontological is. Also, the inversion in sentence 4 is another problem. Obviously, the sentence does not contain the same information content as the sentence: Bałagan jest w sypialni [The mess is in the bedroom]. Sentence 5, despite being equivalent in meaning with the sentence Myślenie jest niebezpieczne [Thinking is dangerous], must be treated separately because of the special case government requirements of the verb; its form with the verbal noun functioning as the 
subject of the sentence, on the other hand, is not a singular sentence, since verbal nouns are treated by Kotarbiński as apparent names, and the copula jest [is], according to its interpretation, does not occur here in its basic, corresponding with the Ontological axiom, function. Here we are still referring to Kotarbiński's comments, since these may be treated as explanations of the intuitions accompanying the construction of Ontology (Kotarbiński 1929: 227; Leśniewski 1992: 377 and next).

Descriptive grammar of the Polish language distinguishes, based on structural properties, four separate sets of word forms of the verb BYĆ [to be]: BYĆ 1 (Nom, Instr), BYĆ 2 (Nom1, Nom2), BYĆ 3 (Inf1, Adv), BYĆ 4 (Num1, Loc) (Saloni, Świdziński, 1981: 127), (in the parentheses there are the case government requirements of the verb, while Nom and Nom1 mean the accommodating nominative groups influencing the grammatical form of the verb, and Nom2 is a non-accommodating nominative group). The role of the Ontological epsilon may therefore be taken preliminarily by lexemes BYĆ 1 and BYĆ 2, provided that they will form singular sentences. We are thus faced with formations such as:

1. Piotr jest prawnikiem. [Peter is a lawyer.]

2. Ja jestem feministka. [I am a feminist.]

3. Ojciec Stefana jest dziennikarzem. [Stephen's father is a journalist.]

4. Patton jest "Krwia i flakami". [Patton is "Old Blood and Guts".]

5. Ten cztowiek jest istota myślaca. [This human is a thinking being.]

6. Ta istota myślaca jest czlowiekiem. [This thinking being is a human.]

7. Autor Hamleta jest autorem Makbeta. [The author of Hamlet is the author of Macbeth.]

8. Szekspir jest autorem Ryszarda III. [Shakespeare is the author of Richard III.]

9. Ten niewyspany jest profesorem uniwersytetu. [The sleepy one is a university profesor.]

10. Ty jesteś inteligentny. [You are inteligent.]

11. Maria jest roztargniona. [Maria is light-headed.]

12. Ten czlowiek jest niewyspany. [This human is sleepy.]

13. Najwyższy szczyt świata jest niebezpieczny. [The tallest peak in the world is dangerous.]

14. Ten niebezpieczny jest nieszczęśliwy. [The dangerous one is unhappy. ${ }^{4}$ If we consider the countability of individuals, although limiting the list of such sentences, the productivity of the schemes used here in natural language is still very high. These statements, from a grammatical point of view, must meet the following requirements: The $\mathrm{N}$ value nominal group exist in the singular form. The subject may not be modified by quantifying 


\section{Halina Święczkowska}

expressions, such as każdy [every] or jakiś [some] although this limitation would not interfere with the syntactical accuracy of sentences $1,11,13 .{ }^{5} \mathrm{It}$ is easy to indicate contexts in which these sentences would be semantically correct. In other cases, the existence of such a modifier infringes correctness not only in terms of syntax, but also in terms of meaning. What stands in the way here is the occurrence of a singular personal pronoun as the subject, and in other sentences - a demonstrative pronoun in the same grammatical number, which is a lexical indicator of singular connotation of the whole name group.

The Ontological axiom entails that the position of the subject is reserved for singular names. Singular terms in the Polish language are not the topic of a separate grammatical description, although of course their meaning properties make it possible to separate in a dictionary a certain class of expressions with singular denotations - surely it would include proper names, geographical names, singular personal pronouns, demonstrative pronouns, and rules for the formation of complex name expressions with such denotation (see, the oldest son of Henry VIII of England, the current US president, first Space explorer, etc.). As indicated above, there is some analogy between Frege's theory of names and Leśniewski's approach. For both of them names are independent expressions, and there is no significant difference between the use of such expressions as subjects. However, how should name groups be understood in the so-called conditional cases? Leśniewski assumes that the nominal group in a function different than the subject belongs to the same semantic category as the subject. It means that if A is a singular name, then also B, despite some reservations, must be singular, if it realizes sentences such as A is B. In accordance with the syntactical description of the Polish language, both A and B in sentences with BYĆ 1 and BYĆ 2 are syntactical groups, and $\mathrm{B}$, in a conditional case, adapts to $\mathrm{A}$ and assumes its category of number and gender. Since we are dealing here with an accommodation of syntactical forms then - likewise - the same adaptation may take place in the semantic plane. Therefore, irrespective of whether the proposition is a general name or a proper name, it must refer, in a given sentence context, to the same object as the subject. The sentence context determines the connotation of the name in functions different than the subject. Here we may add that the Ontological axiom serves as a particular filter of sets of all expressions of a language: it assigns those expressions which, fulfilling the axiom, create a set of names in a language. If our reasoning is correct, then we cannot presuppose that a name is singular or general because its connotation (reference) is determined only upon its use in a sentence. Jest [is], therefore, may Ontologically absorb any name which is "accepted" by the 
context, and in it becomes a singular name. For example: Ten człowiek jest niewyspany [This human is sleepy] or Ten niewyspany jest profesorem uniwersytetu [This sleepy one is a university professor]. We must notice that the names czlowiek [human] and spiacy [sleepy], if used as singulars, must occur with a modifier. Otherwise, sentences without the pronoun ten [this] would surely be ambiguous, as burdened with the fallacy of understatement.

We can indicate here a certain rule referring to the transformation of singular sentences which fall under the Ontological axiom. We will notice that in order for the nominal group in sentences in which such group in a relative case (that is, a case other than the nominative) is used as predicatively to be used as the subject of a singular sentence - this group should be clearly made singular. An indicator of such "singularization" in the Polish language is, for example, the demonstrative pronoun ten [this], though it is difficult to list here all indicators of singularity. In the Polish language, which belongs to the group of so called no-article languages, the context is largely responsible for the connotation in a given sentence. Let us compare the sentences:

Jan jest inżynierem [Jan is an engineer].

Inżynier jest Janem [The engineer is Jan]. / Ten inżynier jest Janem [This engineer is Jan].

Jakiś inżynier jest Janem [Some engineer is Jan]. (These sentences only appear to realize the A is B scheme, because in fact the last two of them are identity (sameness) sentences.)

Obecny premier rzadu jest socjaldemokrata [The current prime minister is a social democrat].

Socjaldemokrata jest obecnym premierem rzadu [A social democrat is the current prime minister].

Ten socjaldemokrata jest obecnym premierem rzadu [This social democrat is the current prime minister].

Jakis socjaldemokrata jest obecnym premierem rzadu [Some social democrat is the current prime minister]. (It is the same when a definite description is on the position of a subject.)

We can see that the shift in the syntactical functions of name groups leads to the creation of two different types of sentences with changed order. One group is composed of singular sentences which determine the sameness of the connotation of names acting on the scheme $A$ is $B$, while the other group is composed of sentences which, following a certain philosophical and linguistic tradition, we shall call indeterminate sentences. This tradition weighs upon the interpretation of singular sentences, dominated by Russell's theory of descriptions. Russell's theory is sometimes treated as the 


\section{Halina Święczkowska}

theory which explains the functioning of articles on the basis of the English language; English articles, similarly to the German definite articles, are lexical indicators of the so called category of definiteness, and their usability is determined by specific grammar rules. Descriptive grammars of the Polish language together with grammatical rules do not identify, and, therefore, do not categorise this phenomenon or property of language. The identification of definiteness from the perspective of languages without articles is carried out by providing a list of expressions which, in Polish, may perform the same functions as articles. Definiteness in the Polish language is a deictic category. What decides whether a phrase is used in a definite way is the sentence and situational context of its use. The necessary condition of using an expression in such a manner is the singularity of its connotation. Therefore, Leśniewski's Ontology may be interpreted as a formal theory of definiteness, and the properties of such category form the content of the Ontological axiom. The notion that such an interpretation is possible is indicated in the works of Lejewski (1958: 150-156) 6 in which he proves that the meaning of the Ontological epsilon is equivalent with the meaning of the English "the", which modifies the name groups in descriptive sentences. According to Lejewski, the ontological JEST $[i s]$ determines, so to speak, the denotation of the name group functioning as the subject, just as a definite article does. Passing over a detailed comparative analysis, and especially its accuracy, we want to show an analogy between Lejewski's arguments and the description of Polish sentence syntax. The syntax theory of this language assumes that the case is a selective category of the verb. Therefore, the verb determines the case form of the noun or nouns connecting with the given verbal lexeme. To be clear, the so called inflectional categories may be divided into inflectional syntactical categories (with properties determined within the text) - such as person, number, and gender of the verb, noun case, case, number and gender of the adjective; and inflectional non-syntactical categories (with properties determined only outside of the text) - such as tense and mood of the verb, number of the noun, the degree of comparison of the adjective. The grammatical category whose properties correspond with definite requirements of a given word form against another word form are called selective grammatical categories. It therefore seems that the determination of certain inflectional categories, which might in fact be significant in singular sentences (in particular, the number of the verb), comes from the outside of the sentences and corresponds to the reference chosen by the user of the language. Therefore, the user of the language has to determine each time the fragment of the extra-lingual reality this user speaks of in a given expression. This notion has specific consequences for the analysed 
class of sentences. Lejewski treats "jest" [is] as if it had, apart from the selective categories discussed above, some sort of separate property, which may be called a selective category of denotation. It seems that such approach, at least in the case of the Polish language, is not plausible. It is not true that a reference or denotation of a given name group in a sentence is determined by the verb or its grammatical form. If it were so, it should be manifested morphologically or in some other formal manner. This also applies to the verb BYĆ [to be], even when it occurs in sentences falling under the ontological axiom.

It seems quite remarkable that several remarks by Leśniewski about a certain syntactical construction of the Polish language made while he was building his formal theory sparked interest in the essence of this construction, making it the key to understanding Ontology. I think that Leśniewski's Ontology remains in the same relationship with the Polish language as Russell's theory with the English language. Undeniably, there is a relationship between the ethnic language and the mode of thinking it determines. Due to its structure, the manner of presenting ideas, and characteristics, language may inspire thoughts about a system other than itself, equipped with strict rules and arrangements, which a natural language, as such, lacks. However, it is difficult to assume that the knowledge of the theory of descriptions allows us to infiltrate all of the rules of using English articles or accept that the Ontological axiom generalises some property of subject-predicate sentences in the Polish language. Although there are sentences in the language which realize the Ontological axiom, the Ontological axiom is not, in fact, about those sentences or that language. What is significant and actually interesting is the comparison of how the same idea on the properties of a certain class of expressions is realised in different formal theories and how these theories affect the theory of natural language.

\section{N O T E S}

${ }^{1}$ Leśniewski (1992: 177 and next; 606-628) often commented on the findings of these authors, in particular on their most prominent work, Principia Mathematica. He also pointed to analogies between his own system and the system of formalising mathematics presented by Whitehead and Russell.

2 This terminology was introduced by E. C. Luschei (1962). Quoted from Simons (1992: 230).

${ }^{3}$ Leśniewski (1992: 606) is explicit about the distinctness of his approach, stating, "I did not wish to have to discuss the logical pseudo-problems [...] concerning the substantival or adjectival form of sentences predicates".

4 The translations in square brackets illustrate the meaning of the source sentences as closely as possible. Due to the vast differences between the two languages, such as 


\section{Halina Święczkowska}

the Polish language being a no-article language being one of them, it is impossible to encapsulate in a translation the properties of the two verbs: Polish być and English to be. What is more, in the Polish language, definiteness is a deictic category. Lack of articles in this language allows for various interpretations of sentences in which a nominal group functioning as a subject contains a proper name or a definite description. (Translator's note)

5 See above.

6 See also Hiż (1977: 271-283). Hiż demonstrates that the hierarchy of epsilons in Leśniewski is comparable to the simple theory of types presented in Principia Mathematica, or that it simply imitates it.

\section{B I B L I O G R A P H Y}

Ajdukiewicz, K. (1960). W sprawie uniwersaliów. In K. Ajdukiewicz, Język i znaczenie, vol. 1. Warszawa: PWN.

Black, M. (1944). Russell's Philosophy of Language. In P. Schlip (Ed.), Philosophy of B. Russell.

Frege, G. (1960). On Concept and Object. In P. Geach, M. Black (Eds.), Translations from the Philosophical Writings of Gotlob Frege. Oxford: Basil Blackwell.

Hiż, H. (1977). Descriptions in Russell's theory and in ontology. Studia Logica 4.

Kotarbiński, T. (1966). Gnoseology. The scientific approach to the theory of knowledge. London: Pergamon.

Kotarbiński, T. (1986). Drogi dociekań własnych. Warszawa: PWN.

Luschei, E. C. (1962). The Logical Systems of Leśniewski. Amsterdam: North Holland.

Lejewski, Cz. (1958). On Leśniewski's ontology. Ratio 1.

Lejewski, Cz. (1960). A re-examination of the Russelian theory of descriptions. Philosophy 35.

Leśniewski, S. (1992). Foundations of Ontology. In S. Leśniewski, Collected Works. Warszawa: Kluwer Academic Publishers \& PWN.

Leśniewski, S. (1992). On the Foundations of Mathematics. In S. Leśniewski, Collected Works. Warszawa \& Dordrecht: Kluwer Academic Publishers \& PWN.

Saloni, Z. Świdziński, M. (1981). Składnia wspótczesnego języka polskiego. Warszawa: Wydawnictwa UW.

Rickey, V. F. (1977). A Survey of Lesniewski's Logic. Studia Logica 4.

Simons, P. (1992). On understanding Leśniewski. In P. Simons, Philosophy and Logic in Central Europe from Bolzano to Tarski. Dordrecht: Kluwer Academic Publishers.

Simons, P. (1992). Leśniewski's Logic and its Relations to Classical and Free Logics. In P. Simons, Philosophy and Logic in Central Europe from Bolzano to Tarski. Dordrecht: Kluwer Academic Publishers.

Woleński, J. (1985). Filozoficzna szkoła Lwowsko-warszawska. Warszawa: PWN. 